\title{
Escrita à mão no Ensino Superior: analisando anotações de alunos de design gráfico do IFPB Cabedelo
}

\author{
Handwriting in graduation: analyzing notes by students from IFPB Cabedelo
}

\author{
Wingrid Dunes Ribeiro, Renata Amorim Cadena
}

design da informação, anotações, escrita à mão, design na educação

Este trabalho teve como objetivo investigar a prática da escrita à mão dos alunos do curso de design gráfico do IFPB campus Cabedelo. A pesquisa resultou em um projeto de iniciação científica, em 2019, e se desenvolveu na monografia do Curso de Design gráfico apresentado em 2010. A metodologia aplicada teve como base os estudos de Sue Walker (2001) e o modelo desenvolvido por Cadena (2018) para análise de artefatos educacionais similares. O tema é de grande relevância, dado o contexto atual em que, conforme comprovaram nossas investigações, a prática da escrita à mão se torna cada vez menos presente diante de outras opções tecnológicas, e até então poucos estudos têm sido feitos sob o viés da linguagem gráfica da escrita à mão. Os resultados obtidos reafirmam tal tendência e evidenciam particularidades que distinguem as anotações dos alunos recém ingressos ao curso das dos concluintes.

information design, note taking, handwriting, design in education

This paper presents the results of a research on handwriting practice among Graphic design students in IFPB campus Cabedelo. This research is the continuation of a scientific initiation project that the author took part in 2019, and then was developed into her monography, presented in 2020. The methodology was based on Sue Walker's studies (2001), as well as the framework created by Cadena (2018) in her research involving similar educational artifacts. This subject is highly relevant, given the current context of handwriting becoming less and less used in face of other technological alternatives, as we could verify during the development of this work. At the same time, there are not many known studies being published approaching the graphic language of handwritten notes. The results confirm such tendency, and present particularities that distinguish notes produced by fresher from the ones made by veteran students.

\section{Introdução}

Dos poucos estudos disponíveis que focam na estruturação e na formação da linguagem gráfica utilizada nas anotações, estão as pesquisas de Sue Walker (2001) sobre escrita à mão por não-designers, que serviram grandemente para fundamentar este trabalho. Os nãodesigners equivalem aqui aos alunos recém ingressos, que ainda não cursaram as disciplinas relacionadas ao design da informação, e nem passaram pelo tempo de vivência do curso que contribui para sua formação como designer.

Anais do $10^{\circ} \mathrm{CIDI}$ e $10^{\circ} \mathrm{CONGIC}$

Kelli C.A.S. Smythe, Rafael de Castro Andrade (orgs.)

Sociedade Brasileira de Design da Informação - SBDI

Curitiba | Brasil | 2021
Proceedings of the $10^{\text {th }} \mathrm{CIDI}$ and $10^{\text {th }}$ CONGIC

Kelli C.A.S. Smythe, Rafael de Castro Andrade (orgs.)

Sociedade Brasileira de Design da Informação - SBDI Curitiba | Brazil | 2021 
A outra autora sobre a qual nos apoiamos foi Cadena (2018), com sua pesquisa sobre a linguagem gráfica da escrita à mão por alunos e professoras em escolas primárias,que resultou na criação de um framework analítico que usamos na metodologia desta pesquisa. Esse instrumento é focado no levantamento e classificação das ferramentas gráficas, termo que teve origem nos estudos de Gilreath (1993, apud Cadena, 2018) para se referir aos itens do vocabulário tipográfico de que cada pessoa dispõe para utilizar em seus documentos.

Entre as descobertas de Cadena (2018), revelou-se em que grau os alunos copiavam fielmente em seus cadernos o que lhes eram passados no quadro, e quais itens eram colocados por conta própria ("ferramentas gráficas exclusivas"). O resultado sugere que, já nesse nível escolar, a caixa de ferramentas gráficas dos alunos tem outras influências que não apenas das professoras. Sendo assim, espera-se que no Ensino Superior as anotações dos alunos reflitam uma bagagem de vocabulário gráfico extracurricular ainda maior.

\section{Metodologia}

Nosso material de estudo foi composto por um total de 12 amostras de voluntários do primeiro e do sexto período, sendo 6 de cada. Esses alunos permitiram que seus cadernos fossem fotografados, e assinaram um termo de consentimento para participação na pesquisa.

Tabela 1: Disciplinas cujas aulas geraram as anotações

\begin{tabular}{llll}
\hline Primeiro Período & \multicolumn{3}{l}{ Sexto Período } \\
\hline Disciplina & Amostras & Disciplina & Amostras \\
Empreendedorismo & 3 & História da arte & 5 \\
Quadrinhos, animação e games & 1 & Cor, forma e percepção & 1 \\
Planejamento Visual IV & 1 & & \\
Libras & 1 & & \\
\hline
\end{tabular}

As amostras foram abordadas segundo os 4 Princípios do design, que Williams (1995) usa como critérios básicos para criar e distinguir layouts de qualidade mais amadora ou profissional: alinhamento, proximidade, repetição e contraste.

Seguidamente, usou-se o modelo de Cadena, que consiste em classificar as ferramentas de acordo com 4 categorias:

- Ferramenta: identifica o elemento utilizado.

- Tipo: a natureza gráfica da ferramenta.

- Espacial. Ex: colunas, linha, recuo.

- Alfanumérica. Ex: números, marcadores.

- Pictórico-esquemática. Ex: conectores, contêineres de texto. 
- Nível: em que escala essa ferramenta atua no layout:

- Palavra: se detém a uma unidade isolada da anotação.

- Subgrupo: os itens que compõem os grupos, como linhas ou parágrafos.

- Grupo: afeta divisões do documento, como blocos, títulos.

- Documento: quando compromete todo layout da página (a exemplo de colunas dividindo a página).

- Função: com que intenção essa ferramenta foi empregada, visto que uma mesma ferramenta pode ser usada para funções variadas em um mesmo documento:

- Importância: estabelece distinção entre itens ou grupos.

- Pertencimento: ajuda a estabelecer o agrupamento e divisões no documento.

- Significado: convenções gráficas encontradas no texto (ex: asterisco para nota de rodapé).

- Tom: atributos arbitrários decorrentes do estilo pessoal de cada aluno, ou cuja natureza não esteja clara.

Para representar didaticamente $\mathrm{o}$ instrumento, mostramos a ficha a seguir por ser mais ilustrativa do que a planilha que na realidade foi utilizada.

Figura 1: Ficha ilustrativa do método analítico. Fonte: adaptação de imagem de Cadena (2018)

\section{Ficha para análise das anotações}

1. Nome do arquivo:____ José01p1.jpg
a) Necessidade:_Listar itens
b) Ferramenta gráfica: Virgula
c) Função: $\quad$ Importância
- Pertencimento
Significado
O Tom
d) Função específica: $\quad$ Texto
O Parágrafo O Título O Data
- Itens
e) Tipo:
- Alfa-numérica
Picto-esquemática
O Espacial
f) Nível de influência:
O Documento
O Grupo
- Subgrupo
O Palavra

2. Nome do arquivo:

a) Necessidade: b) Ferramenta gráfica:

A metodologia incluiu ainda entrevista não-estruturada com alunos do curso e análise documental do Projeto Pedagógico do Curso, permitindo delinear o contexto da nossa amostra. 


\section{A análise das amostras}

Nos deparamos em um cenário em que não foi encontrado nenhum aluno do P6 que anotasse em aula. No primeiro período (P1), apenas 3 alunos possuíam anotações de aula para serem analisadas, de modo que foram reunidas as amostras dos ingressos de 2019.1 e 2019.2 para conseguir o total de 6 . Todas as 6 amostras do sexto período (P6) foram provenientes de 2019.2.

A distinção da presença ou não de pauta nos cadernos se torna relevante, conforme apontou Walker (2001), ao passo que influencia na composição da página.

Tabela 2: Descrição dos suportes utilizados para as anotações. Fonte: a autora

\begin{tabular}{llll}
\hline Período & Suporte & Formato & Pautado \\
\hline & Caderno & $200 \times 275$ & Sim \\
Caderno & $200 \times 276$ & Sim \\
Primeiro & Sketchbook & A5 & Não \\
& Caderno & $200 \times 276$ & Sim \\
& Caderno & $200 \times 277$ & Sim \\
& Bloco de notas & A6 & Sim \\
\hline Papel avulso & A6 & Não \\
Sexto & Sketchbook & A5 & Não \\
& Sketchbook & A5 & Não \\
& Sketchbook & A5 & Não \\
Caderno & A5 & Não \\
& Caderno & A5 & Não \\
\hline
\end{tabular}

\section{Análise gráfica dos Princípios do design nas anotações}

Primeiro período

- Alinhamento: há preferência pelo alinhamento à esquerda, inclusive do título.

- Proximidade: exceto por duas das amostras que apresentaram um layout disperso (Figura 2 a,f), observa-se um padrão de subtítulo próximo a seus respectivos itens.

- Repetição: em termos de estruturas, a maioria utiliza a repetição para estabelecer divisões claramente visíveis.

- Contraste: no emprego mais usual desse princípio, os títulos, a maioria tentou distinguílo com sublinhado e/ou ferramentas espaciais sutilmente aplicadas como diferença de alinhamento, quebra de linha, linha extra. 
Figura 2: Amostras do primeiro período. Fonte: a autora .

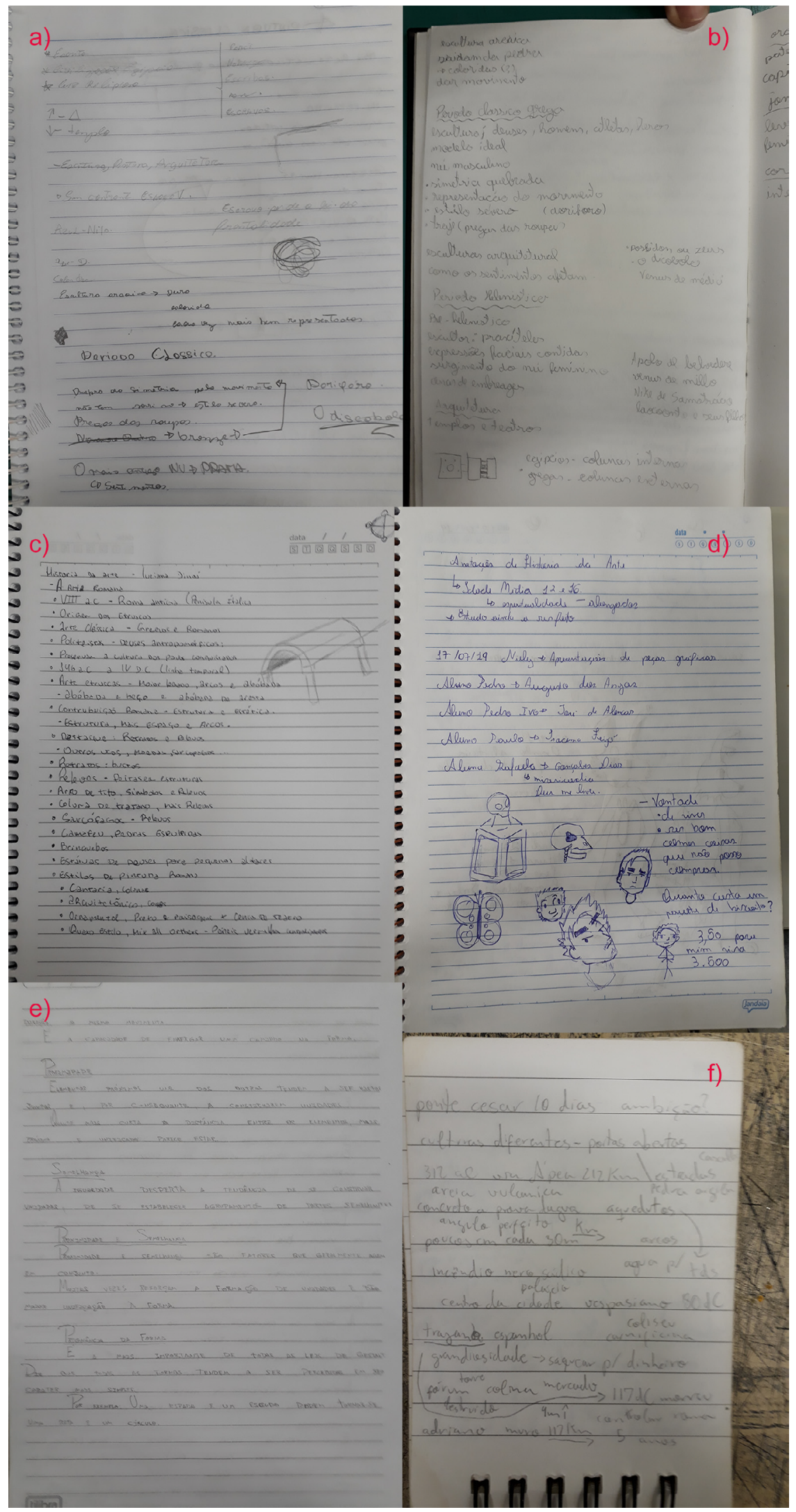

Anais do $10^{\circ}$ Congresso Internacional de Design da Informação | CIDI 2021

Proceedings of the $10^{\text {th }}$ Information Design International Conference | CIDI 2021 
Sexto período

- Alinhamento: Ao contrário do P1, eles tendem a utilizar mais a centralização nos títulos principais, e a diferença de alinhamento (recuo) dos subtítulos em relação ao corpo do texto é mais marcada.

- Proximidade: essas anotações passam uma impressão de usar melhor os espaçamentos, dando mais "respiro" entre as partes da composição.

- Repetição: vemos o uso consistente das ferramentas articulando os agrupamentos estabelecidos em cada anotação. Também vemos uma variedade maior de ferramentas para a mesma função de ancorar os subgrupos (marcadores).

- Contraste: ferramentas de destaque são amplamente utilizadas, resultando em layouts ricos em pistas visuais e facilitando a acessibilidade das informações.

\section{Dados obtidos com a análise das ferramentas gráficas}

Informações obtidas a partir do framework de Cadena (2018):

- Ferramentas: foram listadas 30 no total, das quais 15 são comuns entre os dois grupos.

Gráfico 1: Comparação das ferramentas gráficas levantadas nas duas turmas. Fonte: a autora.

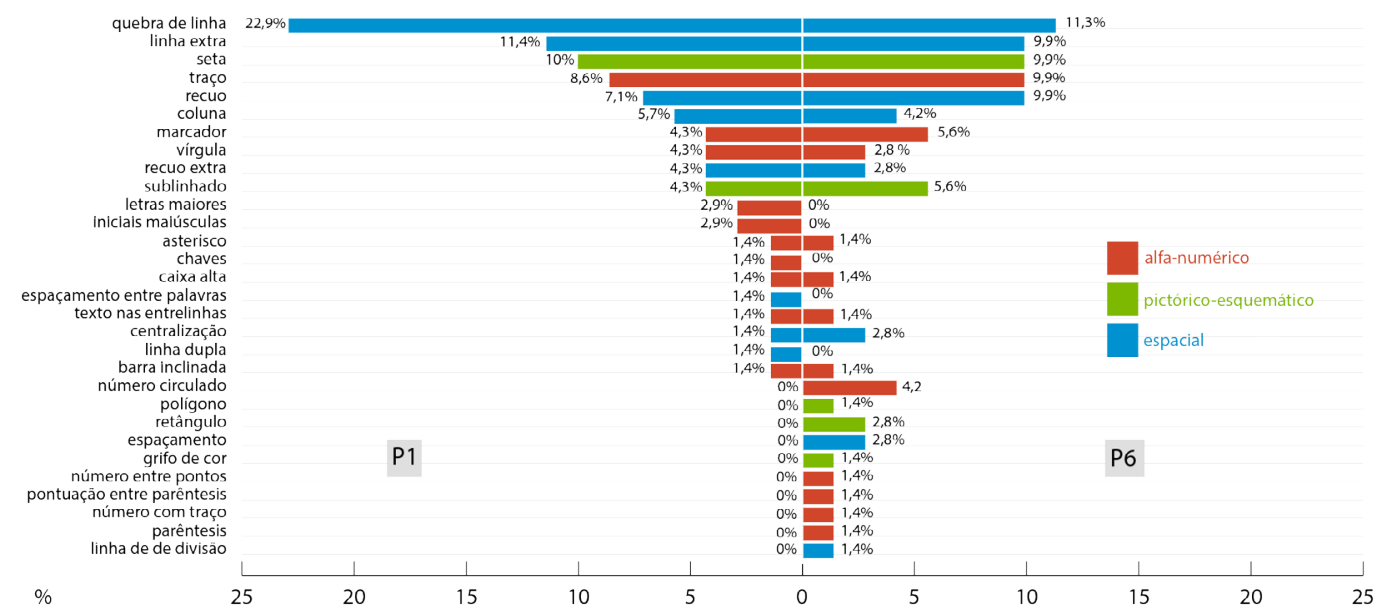

- Tipos: no total, alfanumérico tem maior diversidade de ferramentas. Enquanto as espaciais, com sua limitada gama de ferramentas, são o tipo mais utilizado. 
Figura 3: Amostras do sexto período. Fonte: a autora.

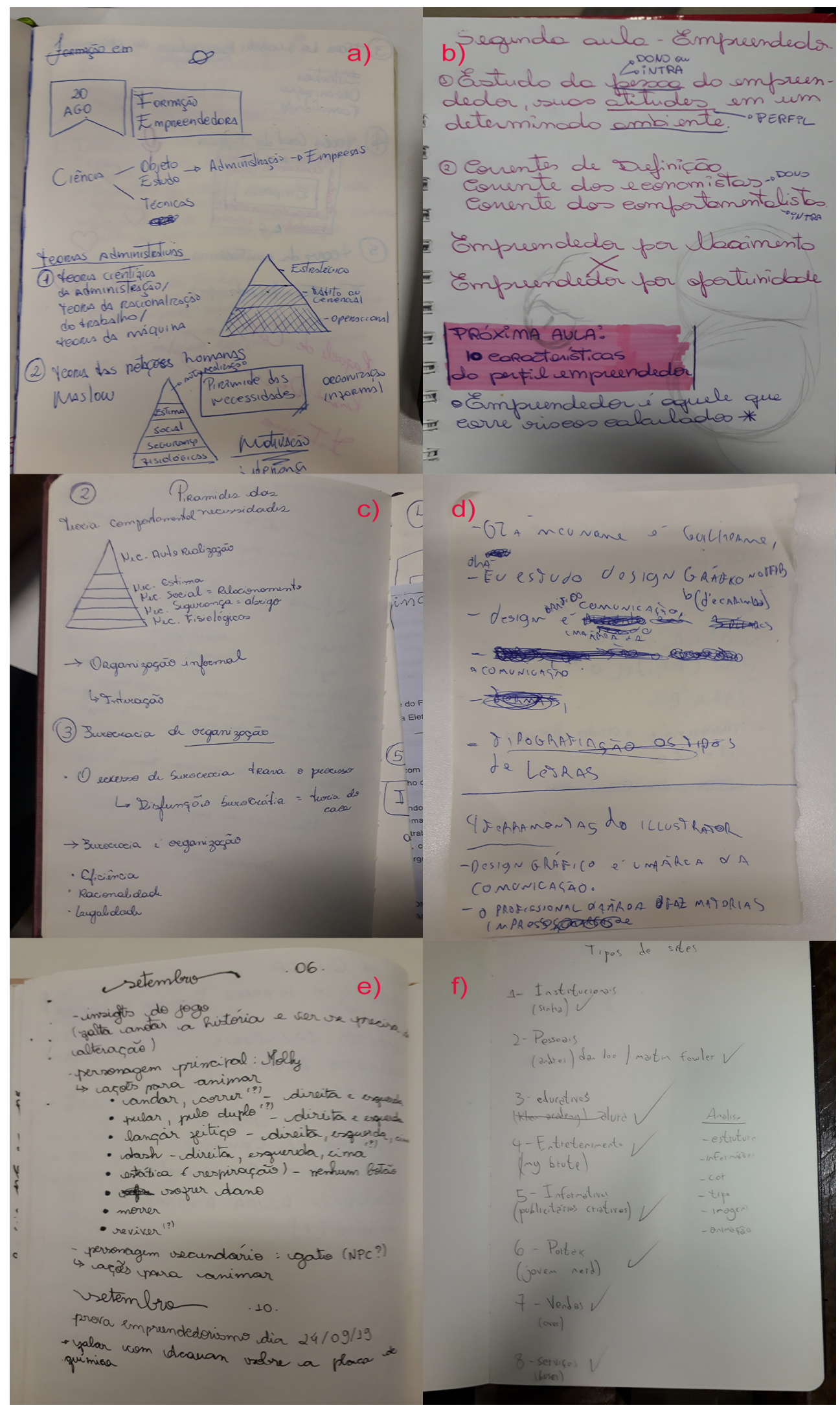


Gráfico 2: Ferramentas gráficas gerais levantadas na pesquisa por tipo. Fonte: a autora

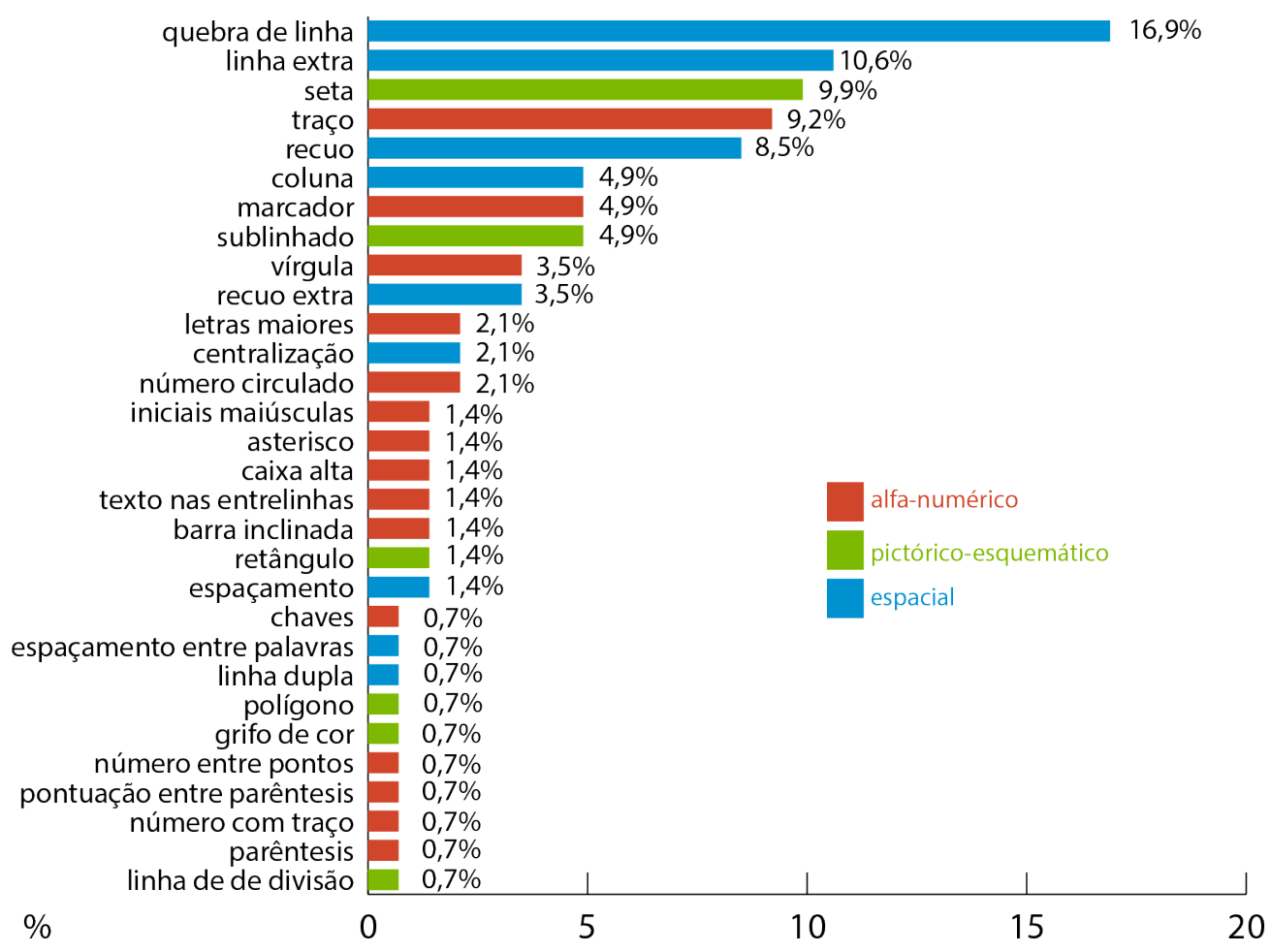

Visualizamos melhor, por turma, a proporção com que cada tipo de ferramenta está presente nas anotações.

Gráfico 3: Tipos de ferramentas gráficas nas duas turmas. Fonte: a autora.
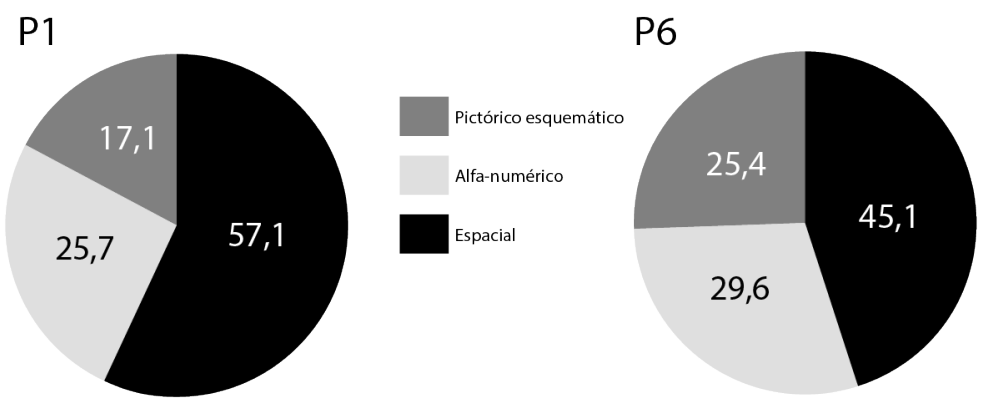

Aqui começamos a perceber as particularidades de cada grupo: a variedade picto-esquemática da caixa de ferramentas do P6 não apenas é maior, quanto eles as conjugam de forma balanceada com os outros tipos de ferramentas.

- Função: pertencimento foi a mais recorrente, o que condiz com a necessidade de estabelecer os agrupamentos e a estrutura de tópicos que predominam nas amostras. 
Gráfico 4: Funções das ferramentas nas anotações das duas turmas. Fonte: a autora.

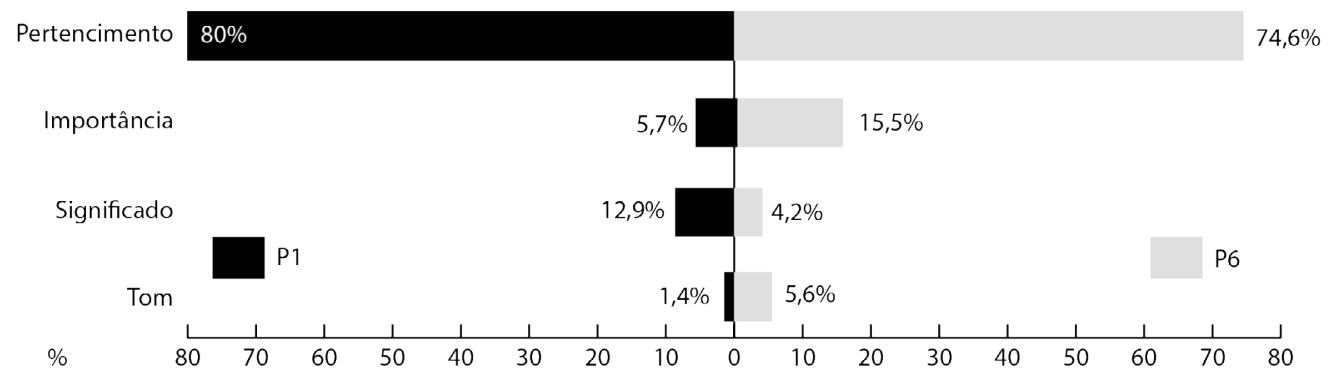

Gráfico 5: Ferramentas recorrentes na função de pertencimento. Fonte: a autora.

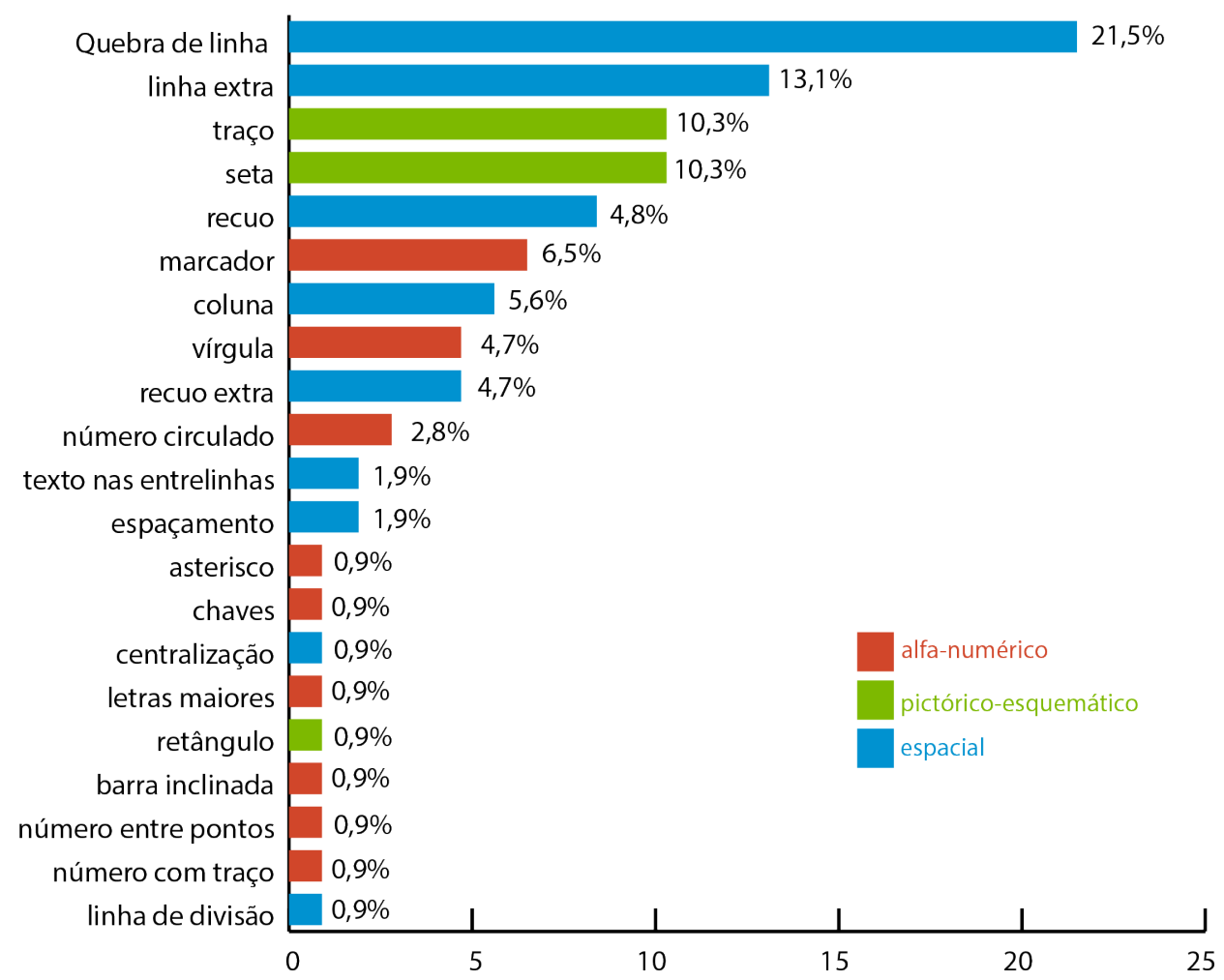

No gráfico 6 podemos visualizar outra informação interessante sobre a caixa de ferramentas geral e o seu caráter situacional: as picto-esquemáticas (verde) prevalecem quando se trata de conferir importância dentro do texto. Em segundo lugar, estão as variações alfanuméricas, e por último, as espaciais. 
Gráfico 6: Ferramentas gerais empregadas na função de importância. Fonte: a autora.

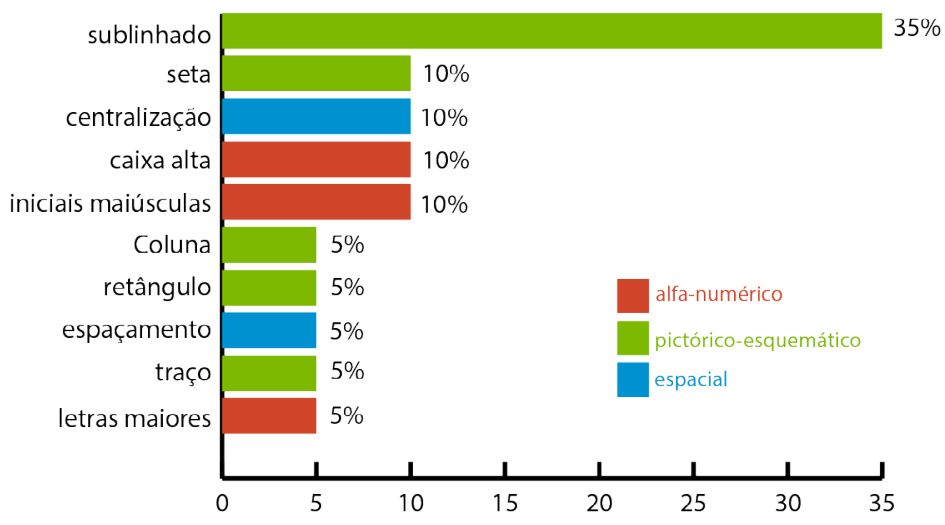

Outro achado que saltou nos dados foi a seta, que se mostrou a mais versátil de toda caixa de ferramentas gráficas levantadas, usadas em quase todas as funções, nas duas turmas.

- Nível: os subgrupos são os níveis em que as ferramentas gráficas são mais requisitadas (gráfico 7). Ambas as turmas convergem no sentido dividir as páginas em subagrupamentos. O P1 usa mais ferramentas espaciais como recuo e quebra de linha, enquanto o P6 utiliza-se de marcadores mais variados, especialmente o picto-esquemáticos.

Gráfico 7: Comparativo dos níveis de atuação das ferramentas gráficas nos dois grupos. Fonte: a autora.

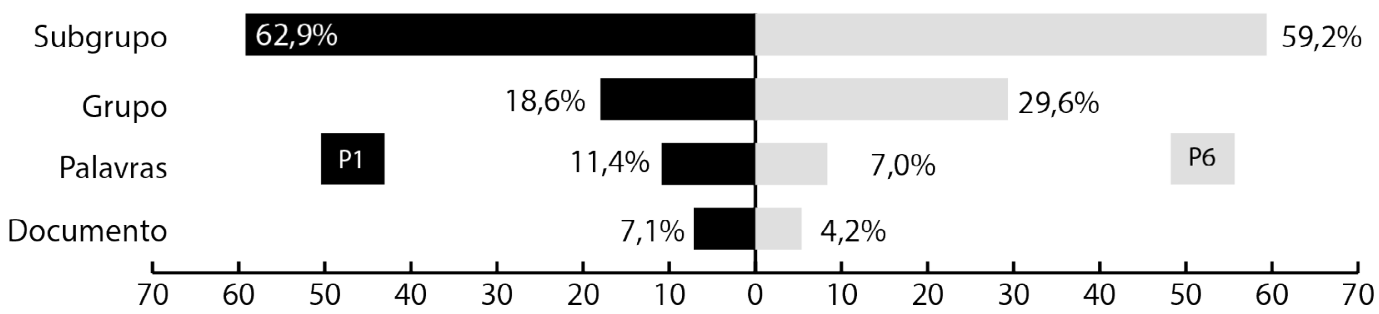


Gráfico 8: Ferramentas gráficas mais utilizadas para articular subgrupos. Fonte: a autora.

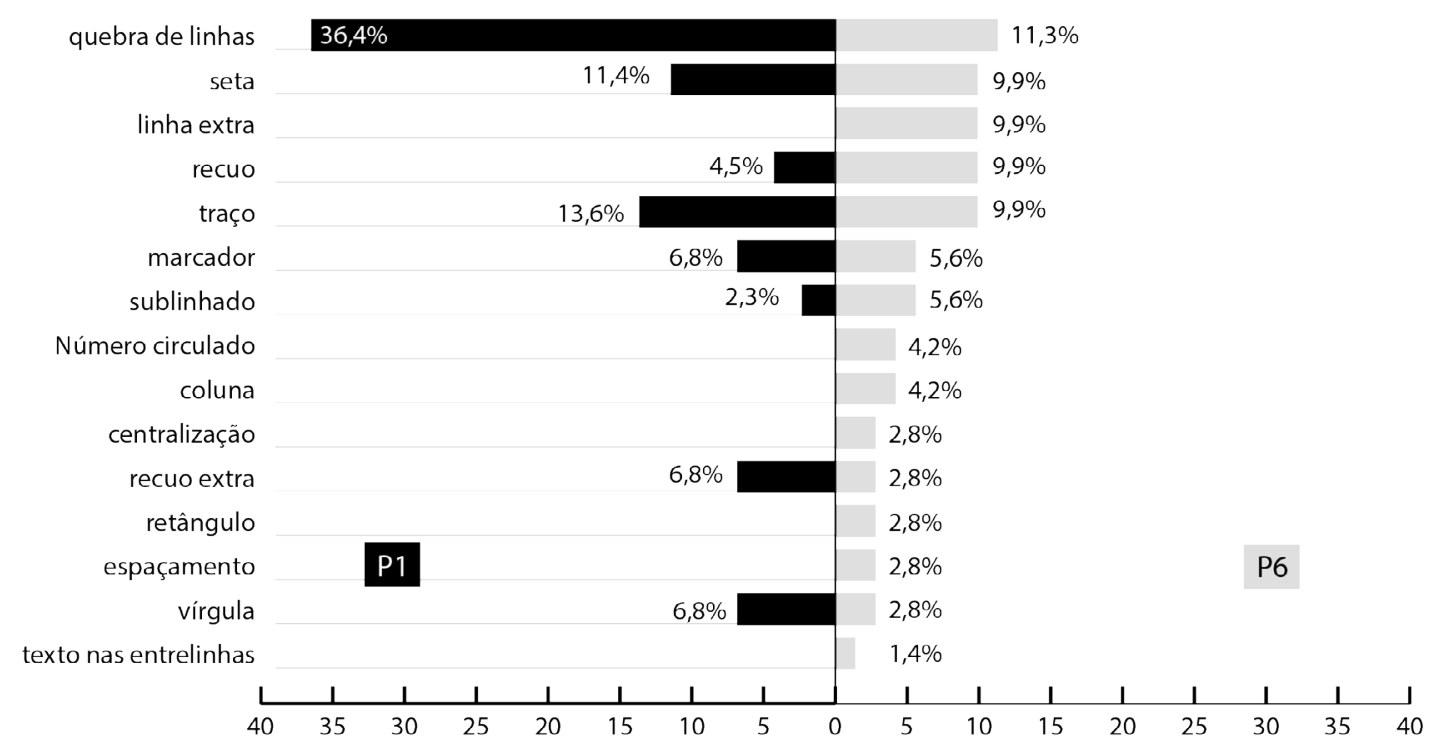

\section{Conclusões e considerações finais}

De modo geral, há uma inclinação dos participantes da pesquisa à estrutura de lista.

Quanto às diferenças levantadas, não há dúvidas de que o suporte escolhido provou-se importar, como bem antecipado por Walker (2001): as páginas sem pauta das amostras do P6 predispõem a elaborações mais adaptativas do que foi possível aos alunos do P1.

A caixa de ferramentas do P6 tende mais às picto-esquemáticos, e observa-se um melhor uso do espaço resultando em melhor organização e aproveitamento do espaço da página. As composições do P1 mostraram-se com pouco uso de contraste e subutilização de pistas visuais a nível de documento. Também neste ponto, nota-se a contribuição das pautas nos resultados verificados, ao passo que sua presença impõe restrições de tamanho aos elementos gráficos da página. Assim, a possibilidade de variação da escala na obtenção de contraste e pistas visuais eficazes é subutilizada nesse grupo (ibiden).

As anotações livres do P6 (figura 3 d,e, f) nos permitem afirmar que há de fato um conjunto de ferramentas gráficas constituído por cada aluno ao longo de sua vida, a partir de influências diversas e de acordo com suas preferências (CADENA, 2018; WALKER, 2001).

\section{Referências}

BRASIL, Ministério da Educação. (2013). Projeto Pedagógico: Curso Superior de Tecnologia em Design Gráfico. https://estudante.ifpb.edu.br/cursos/23.

CADENA, R. (2018). Sharing textual graphic tools: Early lessons in graphic language through practices of handwriting organisation by teachers and pupils in schools in Recife. [Tese não publicada]. PPGDesign. UFPE, Brasil. 
FETTER, S.; LIMA, E.; CATTANI, A. (2017). Letra escolar brasileira: História e formação. In:

M. Bernardes e J. Linden, (Orgs.). Design em Pesquisa - Vol. I. Porto Alegre: Marcavisual, 393-415.

WALKER, Sue. (2001).Typography and language in everyday life: Prescriptions and Practices. Singapore: Pearson Education,.

WILLIAMS, Robin. (1995). Design para quem não é designer: Noções básicas de Planejamento Visual. São Paulo: Callis.

\section{Sobre o(a/s) autor(a/es)}

Wingrid Ribeiro, Tecnóloga em Design Gráfico, Brasil <wingriddunes@gmail.com> Renata Cadena, Dra., IFPB, Brasil <renata.cadena@ifpb.edu.br> 